Measurement of External Forces and

Torques on a Large Pointing System

R. C. Morenus

Ford Aerospace \& Communications Corporation 
MEASUREMENT OF EXTERNAL FORCES AND TORQUES ON A LARGE POINTING SYSTEM

\begin{abstract}
Methods of measuring external forces and torques are discussed, in general and as applied to the Large Pointing System (LPS) wind tunnel tests.

The LPS tests were in two phases. The first test was a preliminary test of three models representing coelostat, heliostat, and on-gimbal telescope configurations. The second test explored the coelostat configuration in more detail. The second test used a different setup for measuring external loads.

Some results are given from both tests.
\end{abstract}

\title{
GENERAL
}

This paper is concerned with what can be done to measure external aerodynamic forces and moments during a wind tunnel test of an airborne telescope system. It is assumed that the primary test objective is high response measurements within the telescope.

It would clearly be desirable to measure both static and dynamic loads, but dynamic response of the model to tunnel vibration and flow fluctuations will tend to swamp readings. It is very difficult to pick out what's happening at frequencies above the model-balance frequency, which tends to be 1 ow. By careful, light weight, statically balanced construction, perhaps with isolation mounts to attenuate base motion, and with careful analysis of the data, it would be possible to obtain useful information, but success would not be assured the first try. This would require a dedicated test, as the weight, friction, and damping of pressure tubes, transducers, and cables would be intolerable.

For these reasons, only static external loads should be considered in a test of this type.

With this restriction, the following points should be kept in mind during test planning.

- Priority: It is assured that external loads will be only part of the total data to be gathered during the test, but what is the relative importance? Will the test be a failure if the external loads data are not usable?

- Cost: How much budget is available for special instrumentation or precision model work?

- Schedule: How much time is available? Schedule and cost considerations make the use of existing, checked-out instrumentation very deisrable. 
- Resolution: Will the selected set-up be able to separate the wheat from the chaff?

- Load Capacity: The loads will often be acting some distance from the geometric center of the balance, so the effective force capacity of the balance may be much smaller than its nominal value. If the balance is greatly over-strength the resolution will suffer, but deflections will be smaller.

- Deflection: Balance and support system deflections are very difficult to calculate, and are almost invariably underestimated. Even where empirical data are available on balance deflections, the compliance of the various joints involved prevents an accurate estimate.

- Dynamics: Where there is deflection and there is mass (and large telescope models tend to be heavy) the model-balance system will have a tendency to oscillate. If there is enough component of the aerodynamic load at or below the model-balance resonant frequencies, oscillations will develop which will increase the total deflection.

- Space Available: The volume and location of the space that is available for the balance may have a strong influence on the design.

Two Examples

Keeping these guidelines in mind, here are a pair of examples of at least partially successful attempts to measure external loads on telescope systems in the Ames 14 foot transonic wind tunnel.

Large Pointing System Phase I Tests

Both tests were conducted during the Large Pointing System (LPS) study. The first test was an exploratory one to obtain preliminary data on three quite different pointing system concepts. The first mode1, shown in Figure 1 , was a coelostat system. It had a fixed horizontal telescope and used two mirrors arranged like a periscope in a large sphere to direct the beam. The outer gimbal was rotation of the sphere about the telescope centerline; the inner was rotation of about one third of the sphere relative to the rest. Only a third of the sphere was exposed to the air flow.

The second model, shown in Figure 2, was a heliostat system, also with a fixed horizontal telescope but with only one mirror mounted in a horizontal drum to point the beam. The outer gimbal is rotation of the drum about the telescope centerline and the inner gimbal is rotation of the mirror about an axis perpendicular to the drum axis. This had very 1 ow aerodynamic drag but a somewhat limited field of view. 


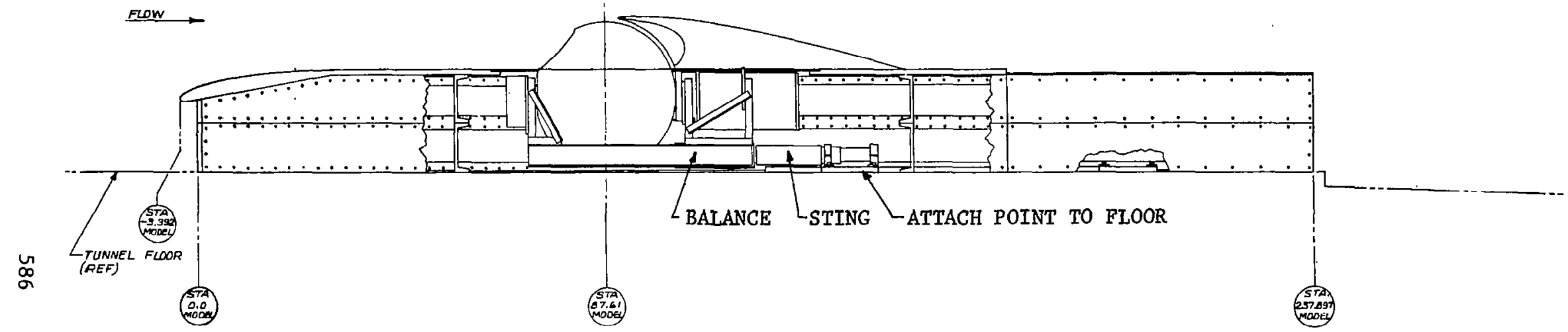

Figure 1. Coelostat Model, Phase I Installation - Side View. 


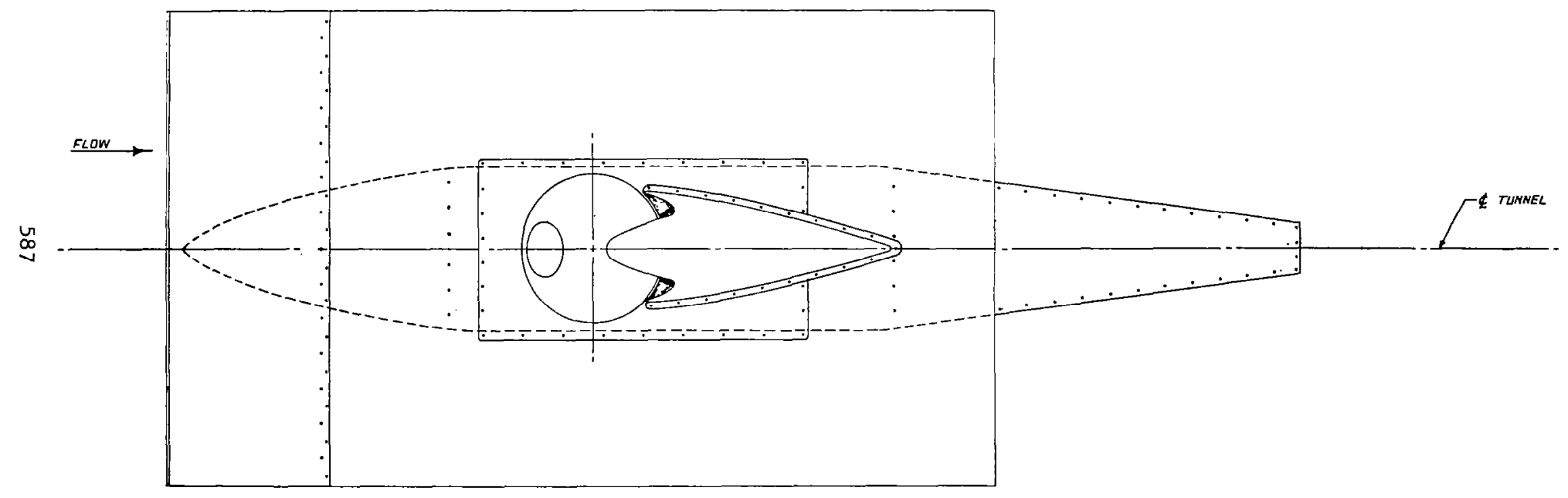

TUNAEL WALL (REF)

Figure 1. (concluded) Coelostat Model, Phase I Installation - Top View. 


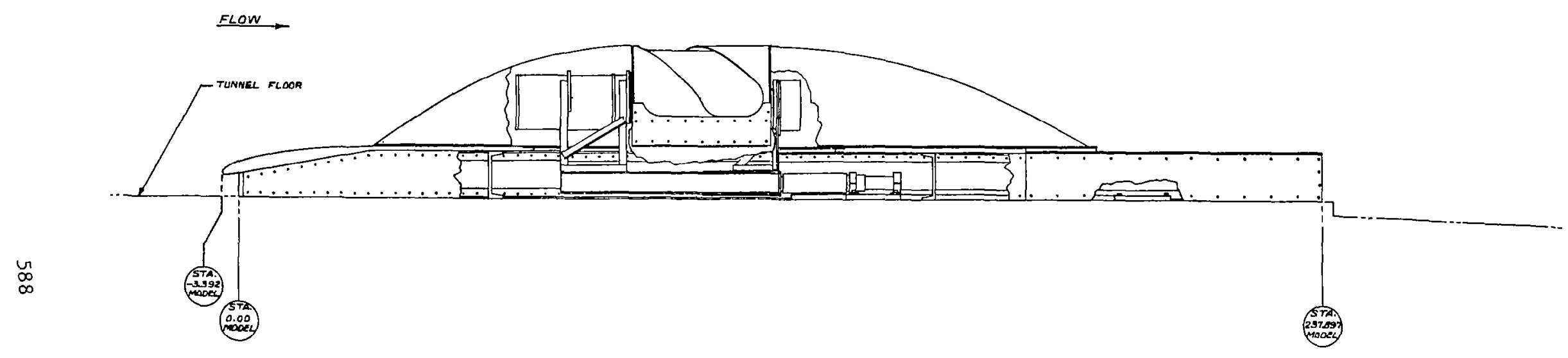

Figure 2. Heliostat Model, Phase I Installation. 
The third model, shown in Figure 3, was an on-gimbal telescope resembling the system used on the Airborne Laser Laboratory. The entire telescope was rotated in azimuth and elevation.

All three models used a common support structure and boundary layer splitter plate. Because the tunnel construction precluded removing large portions of the tunnel walls, the entire large sphere of the first model had to be inside the tunnel. This was done by raising the boundary layer splitter plate and having a large fairing underneath. The other two models used the same arrangement but with the splitter plate lowered to reduce the total frontal area of the model and support assembly.

This would have been an ideal application for an old fashioned external balance found under the floor of most large low speed tunnels, but the 14 foot transonic tunnel did not have one. As a substitute, the largest sting balance available (a 4 inch Task balance) was mounted in a steel platform just above the floor and supported by a stub sting attached to the tunnel floor. In each case the entire telescope system was mounted to the metric platform to avoid the problem of attempting to separate metric and non-metric portions of the optical system.

This was a satisfactory arrangement except for one very important respect: deflection. Both the coelstat and the on-gimbal telescope models developed enough 1 ift to rise into the floor plate and aft fairing, both statically and dynamically. By grinding extra clearance and shimming the sting/floor interface, the coelostat model could be tested, but the extra drag and higher load center of the on-gimbal telescope caused such large deflections that the metric platform had to be bolted to the floor to complete the test program. No problems were encountered with the heliostat because of the much lower load level.

In conclusion, this load measurement scheme provided data which was useful in the LPS study, even though it was never analyzed systematically. Data for the coelostat and on-gimbal telescope are definitely contaminated by unknown magnitudes of contact, or fouling, between the metric and nonmetric portions of the model, but there is no doubt that the measured values are approximately correct and good enough for sizing structure. The deflection problems slowed down the test program but did not prevent it from being completed.

Large Pointing System Phase II Tests

After the phase I tests a study was made using the phase I data to select one configuration for more detailed study. The configuration selected was a modification of the coelostat, adding a limited travel of the upper turning mirror to improve high 


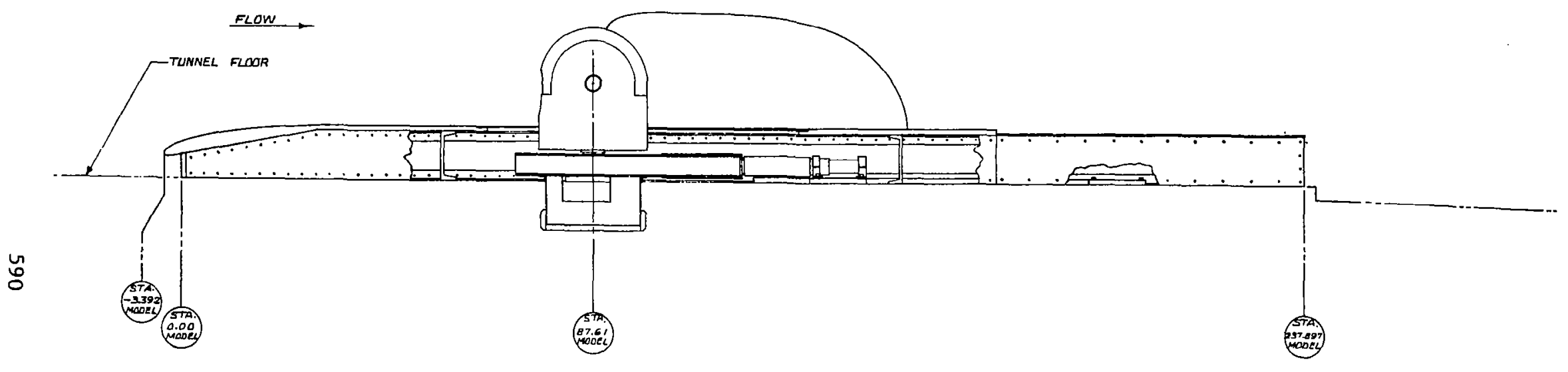

Figure 3. On Gimbal Telescope Model, Phase I Installation. 
frequency response. This did not change the model, except that it was now called a coelostat/heliostat, and what was inner gimbal on the coelostat became middle gimbal on the coelostat/ heliostat.

During the roughly 9 months between the two tests an important change was made to the 14 foot tunnel, however. A large balance was installed below the floor for testing semispan models. This was not perfectly suited for the LPS test because it was only 5 component (lift force, which would be side force on a semispan model, was left out) but it was quite rigid and had ample load capacity. A simple lift link was incorporated in the adaptor which bridged the space between the balance and the metric platform of the model. This is shown in Figure 4.

Several photographs of the phase II model during installation are shown in Figure 5. This is typical of phase $I$, also. Figure 6 shows several of the configuration changes; the external wind screens (EWS) tested in phase I were similar to the phase II screens pictured here.

The new balance arrangement eliminated the deflection problems that had plagued the phase I tests. The results were marred by greater than desired zero shifts, but these were not large enough to render the data useless. After the test, NASA characterized the zero shift problem as temperature related, but it was probably exacerbated by the newness of the balance and installation and the relatively low level of the loads being measured.

TEST RESULTS

In the following pages some sample results are given. In each case the reference area and length are the crossection area and diameter, respectively, of the sphere or the cylindrical portion of the housing that is exposed to the airstream. Moments referenced about the intersection of the outer and inner (middle, for phase II) gimbal axes.

In all the plots which follow Delta 1 is the inner (or middle for phase II) gimba1 deflection, and Delta 2 is the outer gimbal deflection.

Figures 7 and 8 are force and moment data, respectively, for the on-gimbal telescope model, showing the effect of a one inch high 45 percent porosity wind screen. The apparent reduction in drag due to the screen is probably due to small changes in the non-metric fairing; the effect of the screen on yawing moment looks reasonable.

Figures 9 and 10 are force and moment data for the heliostat model, showing the effect of 1 inch and 1.8 inch high wind screens at Mach .7. Figures 11 and 12 are similar data at Mach .85. The forces and moments are predictably small, with the screens showing clearly on drag. 


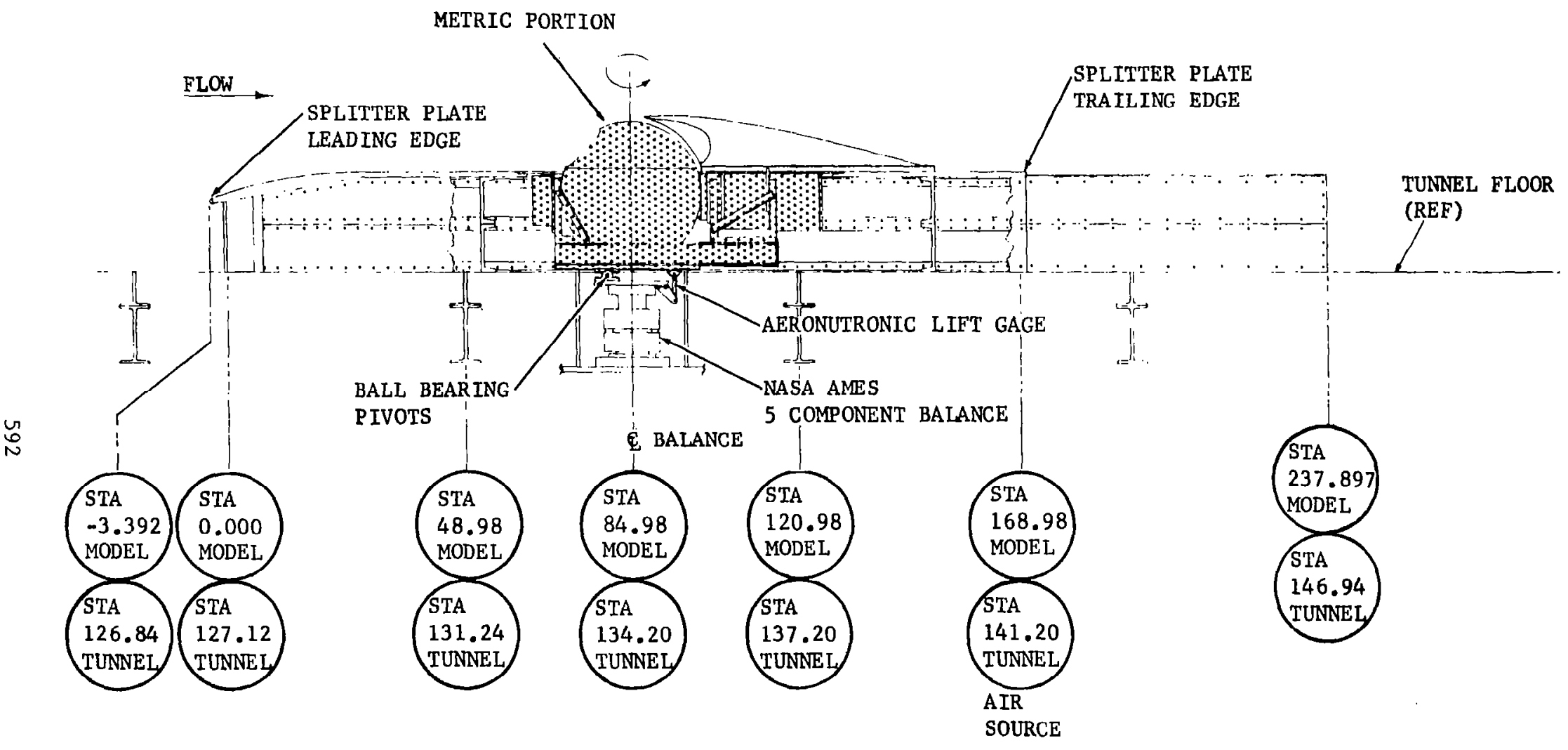

Figure 4. Phase II Model Installation.

NOTE: TUNNEL STATIONS ARE FEET MODEL STATIONS ARE INCHES 


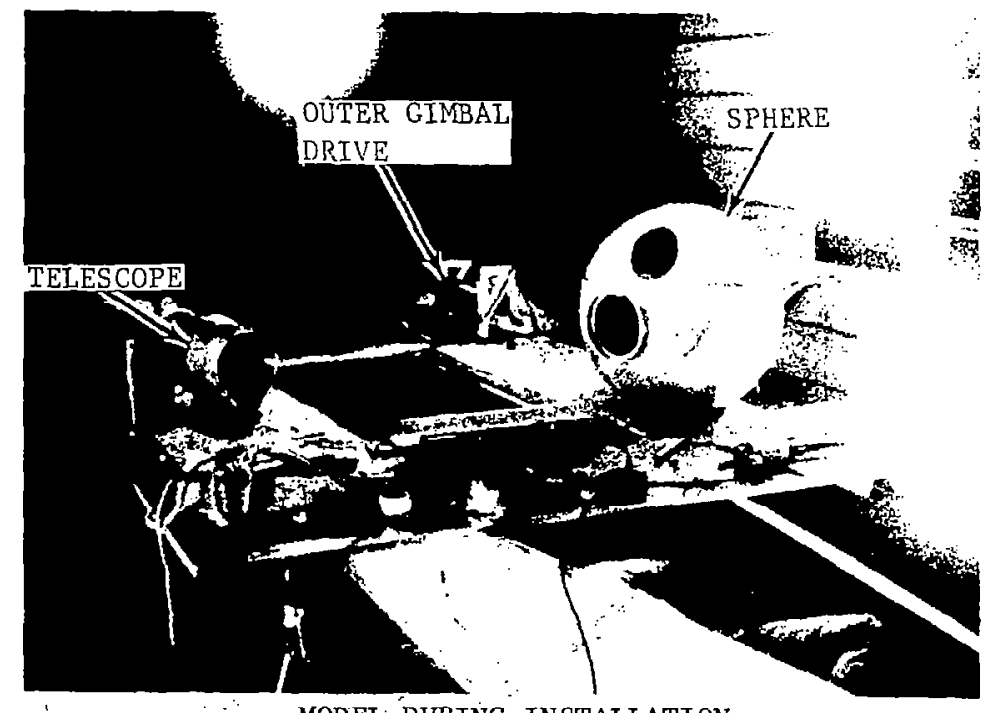

MODEL DURING INSTALLATION

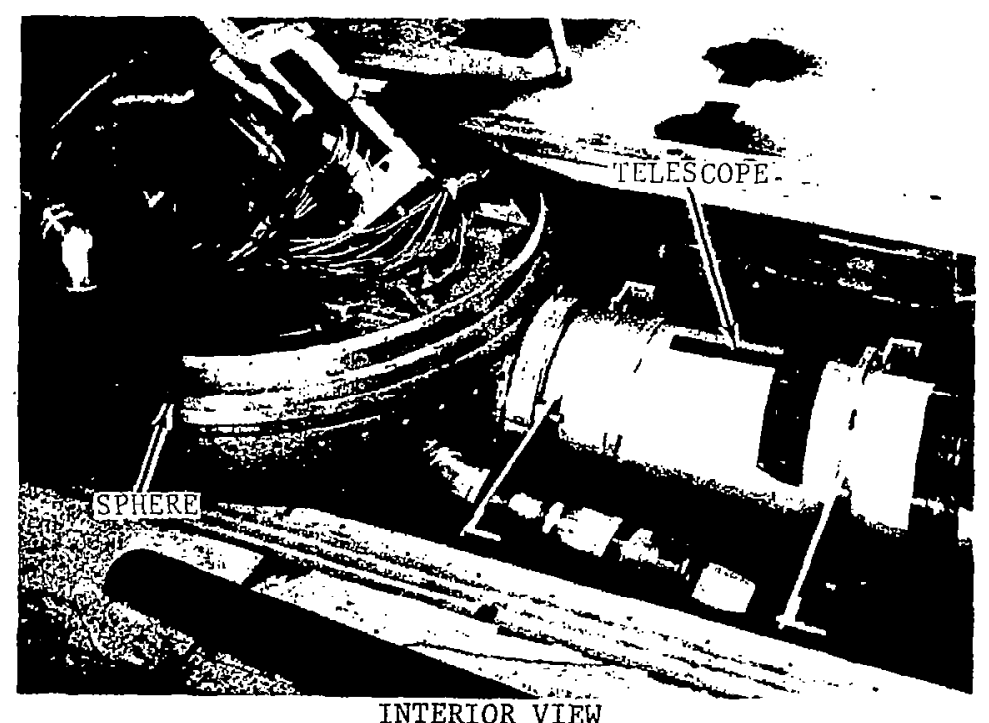

INTERIOR VIEH

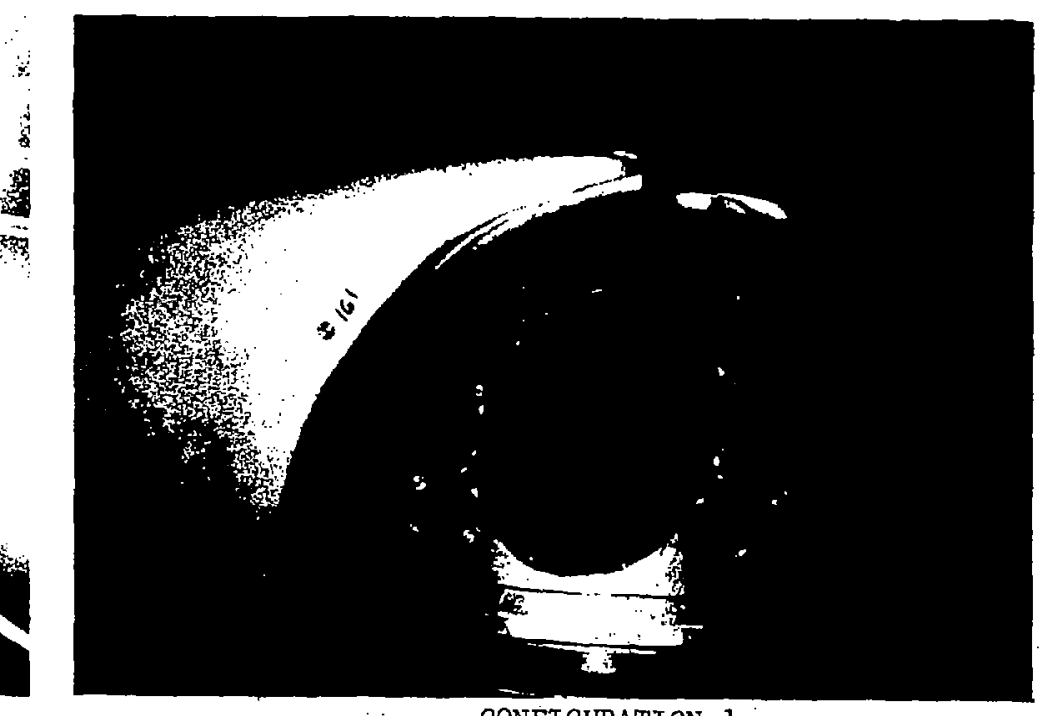

CONFIGURATION 1

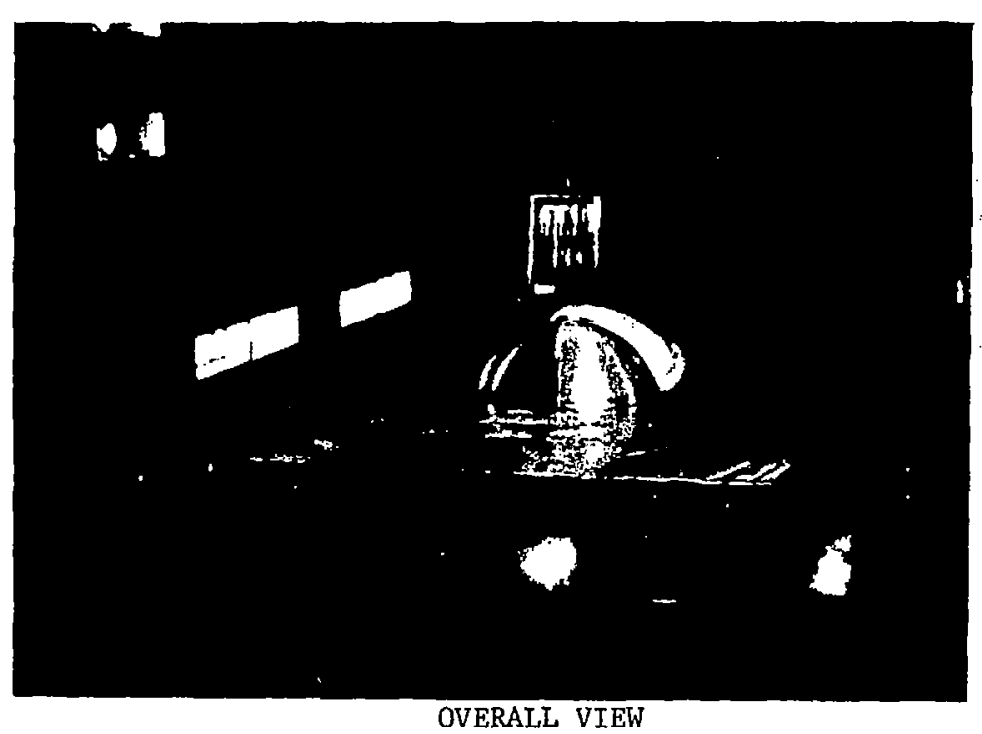

OVERALI VIEW

Figure 5. Photographs of Phase II Installation. 

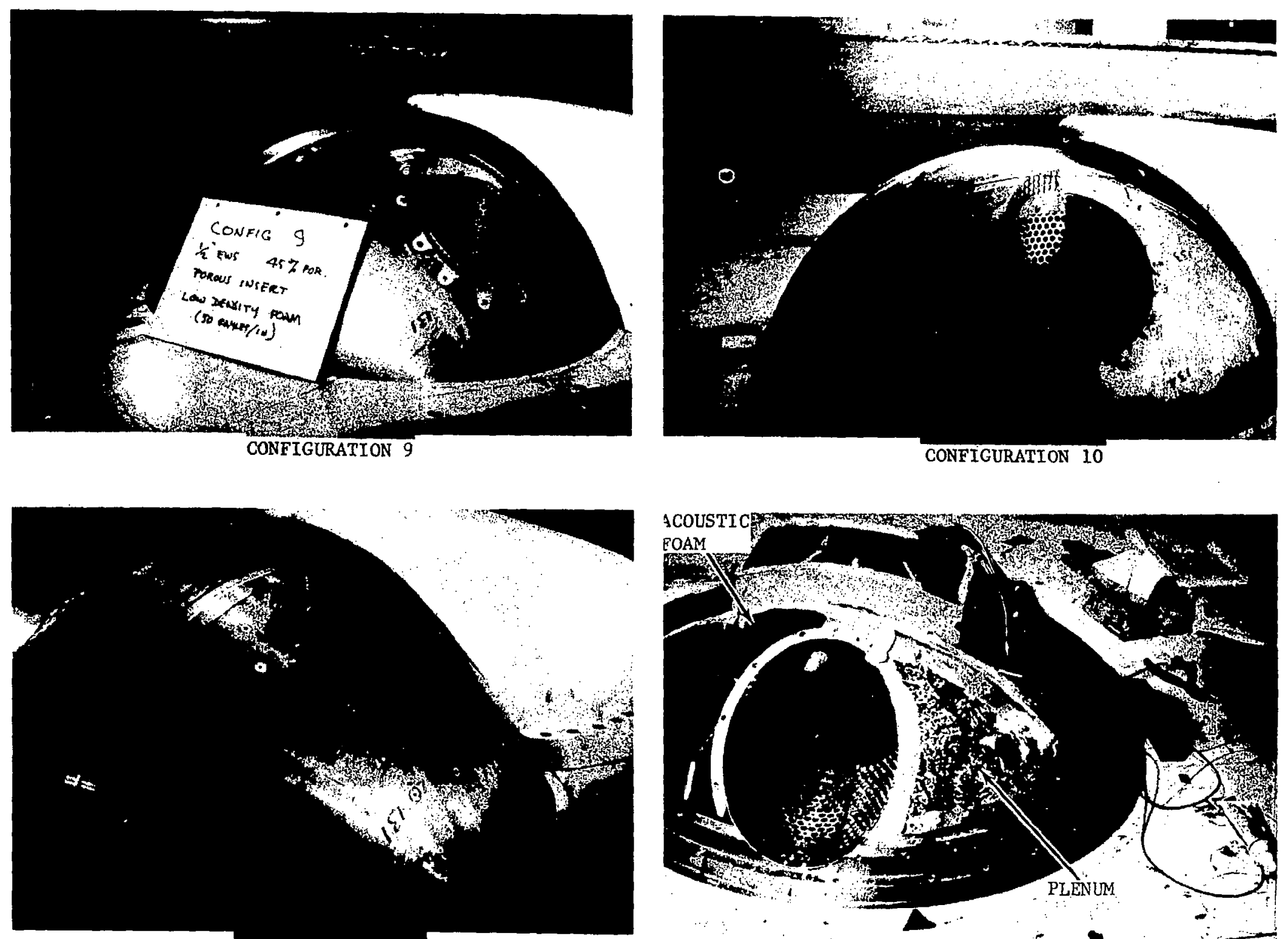

CONFTGURATION 13

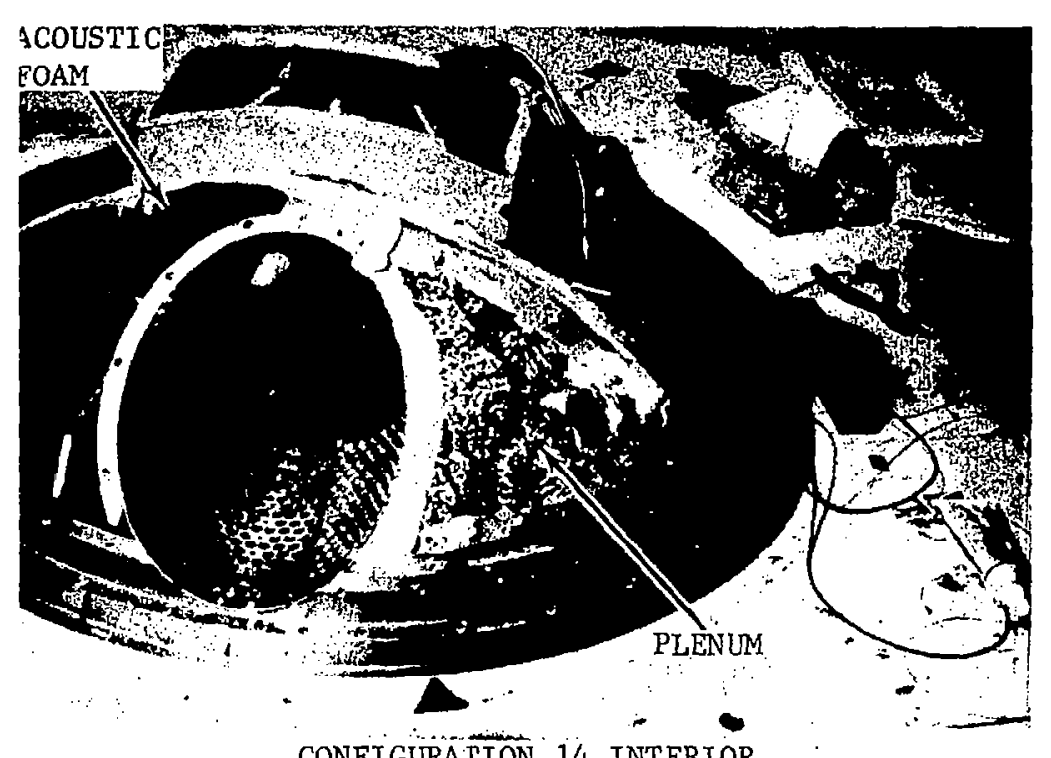

Figure 6. Photographs of Phase II Configurations. 


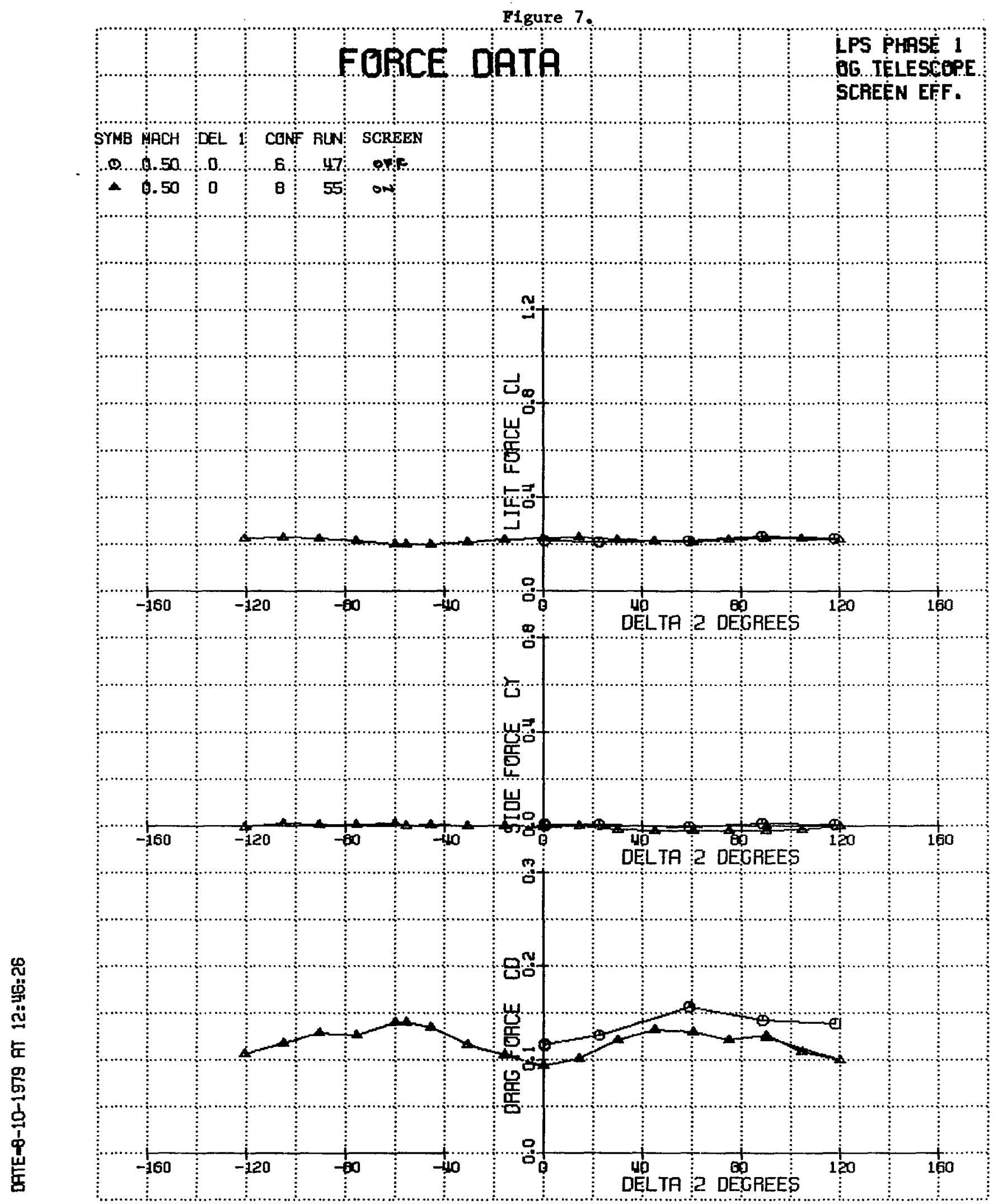


Figure 8.

MOMENT DATA

LPS PHASE 1

OG TELESEGPE

SCREEN EFF.
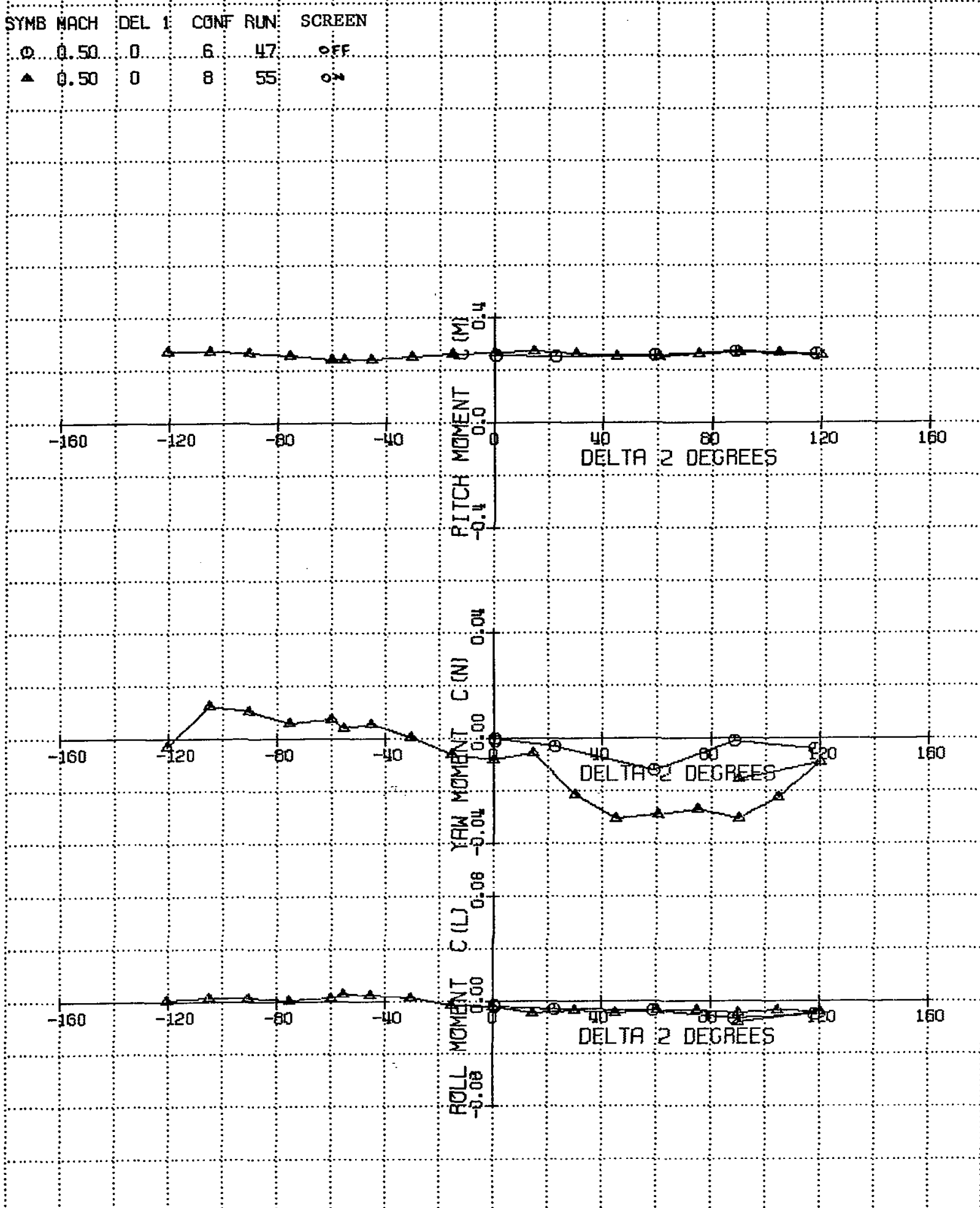
Figure 9.

\section{FORCE DATA}

LPS PHASE 1 HEL.JESTAT

SYMB MRCH DEL I COMF RLN: SCREEN

......

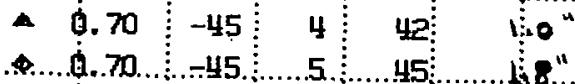

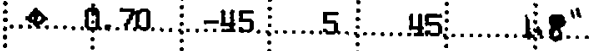
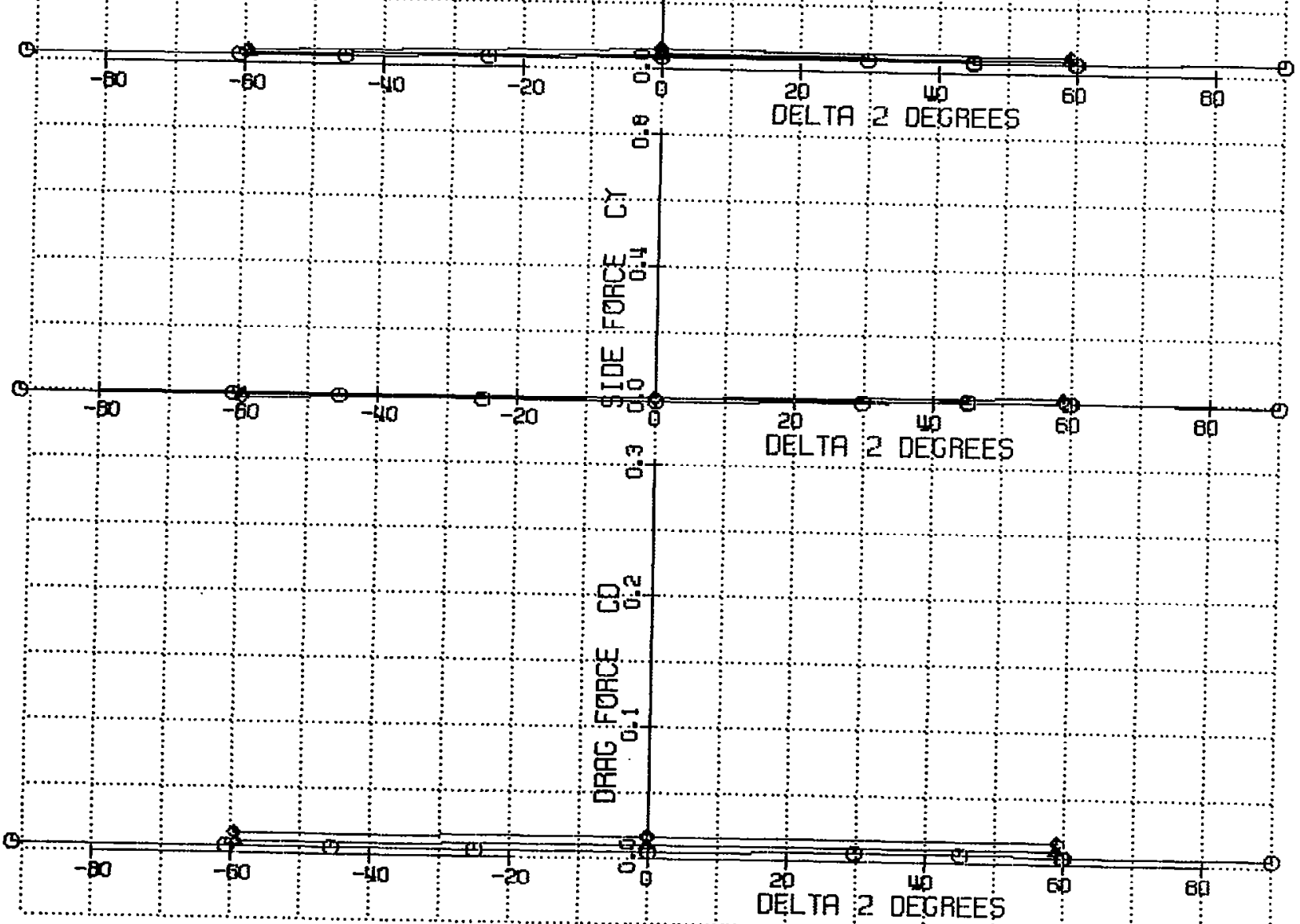
Figure 10.

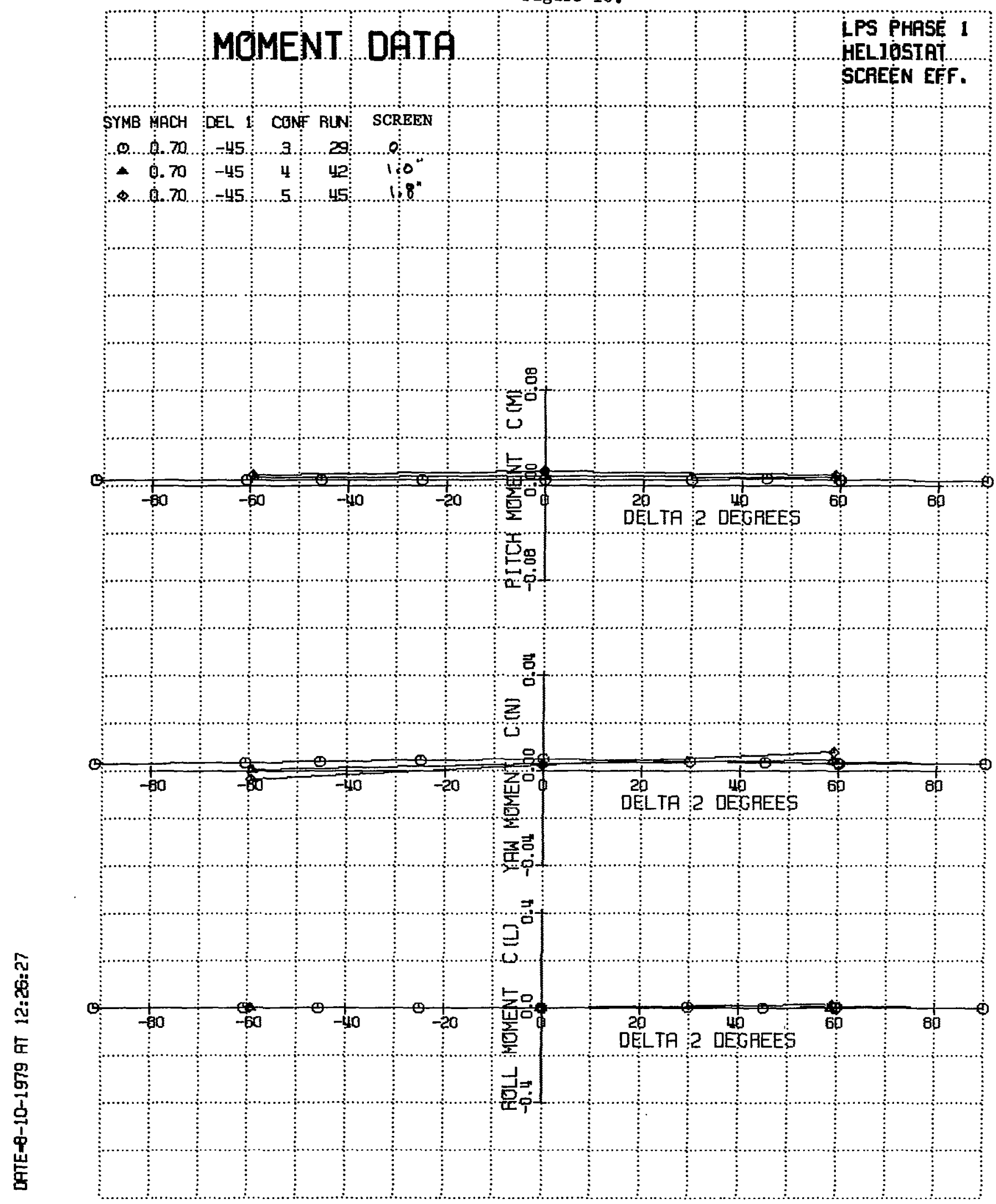


Figures 13 and 14 show force and moment data for the phase I coelostat model, showing the effect of a 1 inch high screen at Mach numbers of .7 and .85 . Figure 15 is the moment about the inner gimbal axis.

The second phase was conducted with the coelostat model from phase I, modified not only with respect to external torque measurement, but also with remote control added to the inner gimbal rotation - which became the middle gimba1 because analysis showed that small motions of the upper turning mirror were desirable. This change from coelostat to coelostat-heliostat was only a matter of nomenclature as far as the model was concerned, because the angular deflection of the new inner gimbal was too small to be of significance aerodynamically.

The addition of remote control to the middle gimbal allowed much more data to be taken per tunnel hour, and also allowed the change to middle gimbal angle as the parameter varied during each run. This change prevents comparing runs directly, but there was ample coverage of the same angles to allow some comparisons to be made.

Figures 16, 17, and 18 show force, moment, and middle gimbal moment for the phase II model with various screen heights at an outer gimbal angle of -90 degrees (with the middle gimbal axis vertical) and Figures 19,20 , and 21 show the same data at an outer gimbal angle of zero (middle gimbal axis horizontal). Some idea of the magnitude of the zero shifts can be obtained from the fact that side force, yawing moment, rolling moment, and middle gimbal moment should all be zero (except for configuration 10, which has an asymmetric screen) at Delta $2=90$ degrees and Delta $1=-90$ degrees.

Figures 22, 23, and 24 show one configuration tested at Mach numbers ranging from 0.3 to 0.92 . The data for Mach 0.3 and 0.5 look particularly erratic, suggesting that the balance is too big to measure small loads accurately.

In conclusion, the balance setup used for phase II was much more satisfactory because it allowed the primary test objectives to be met without delays caused by excessive deflections, but much crossplotting and shifting would be required to use the data for other than approximate loads estimation. 
Figure 11.

FORCE DATA

LPS PHASE 1

HELIOSSTAT

$\begin{array}{lll} & \\ \text { STMB HACH DELL I CONF RUN SCREEN }\end{array}$

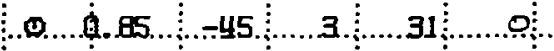

- $6.85-454$ 4 41 1:0"

ه...

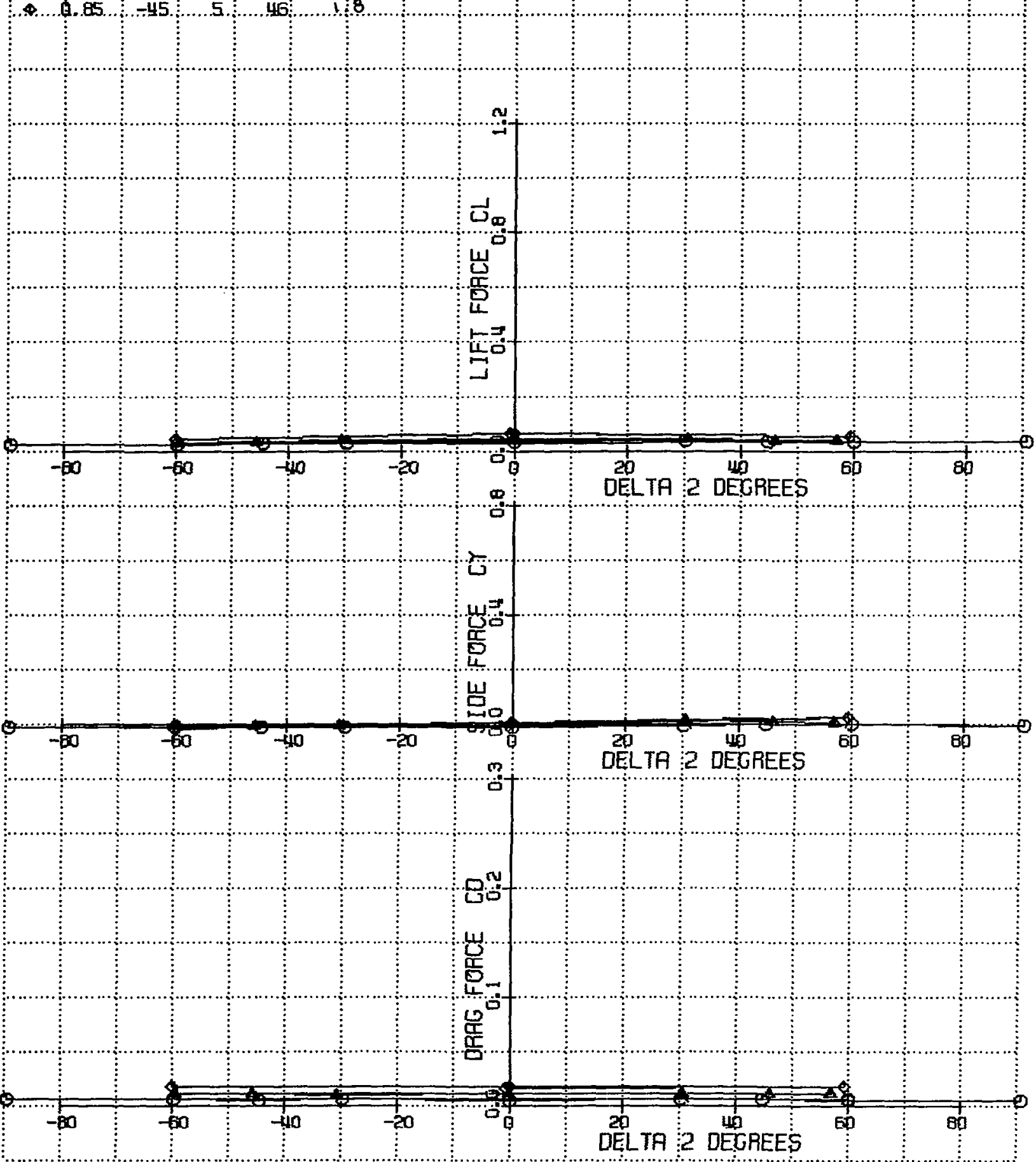




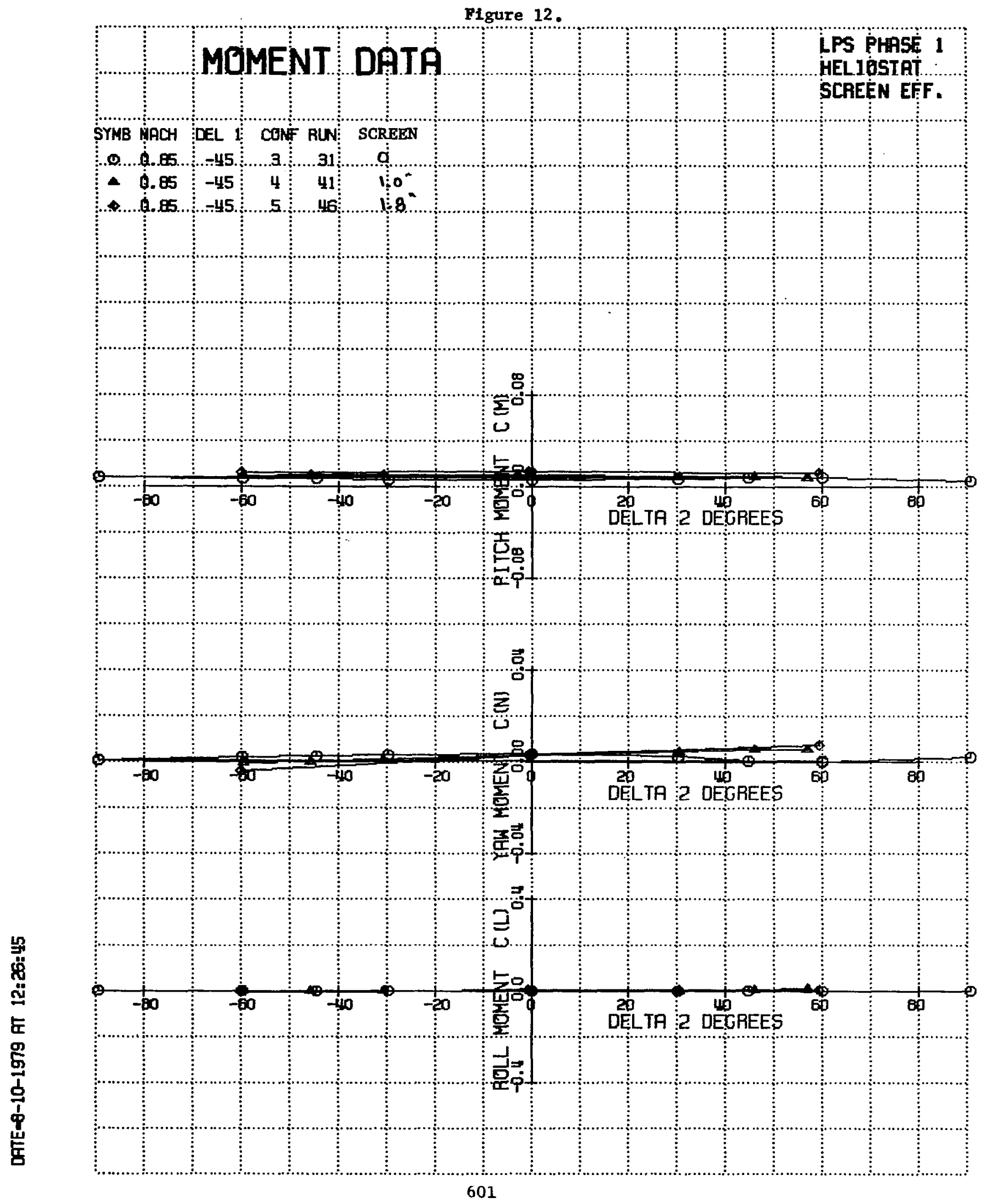




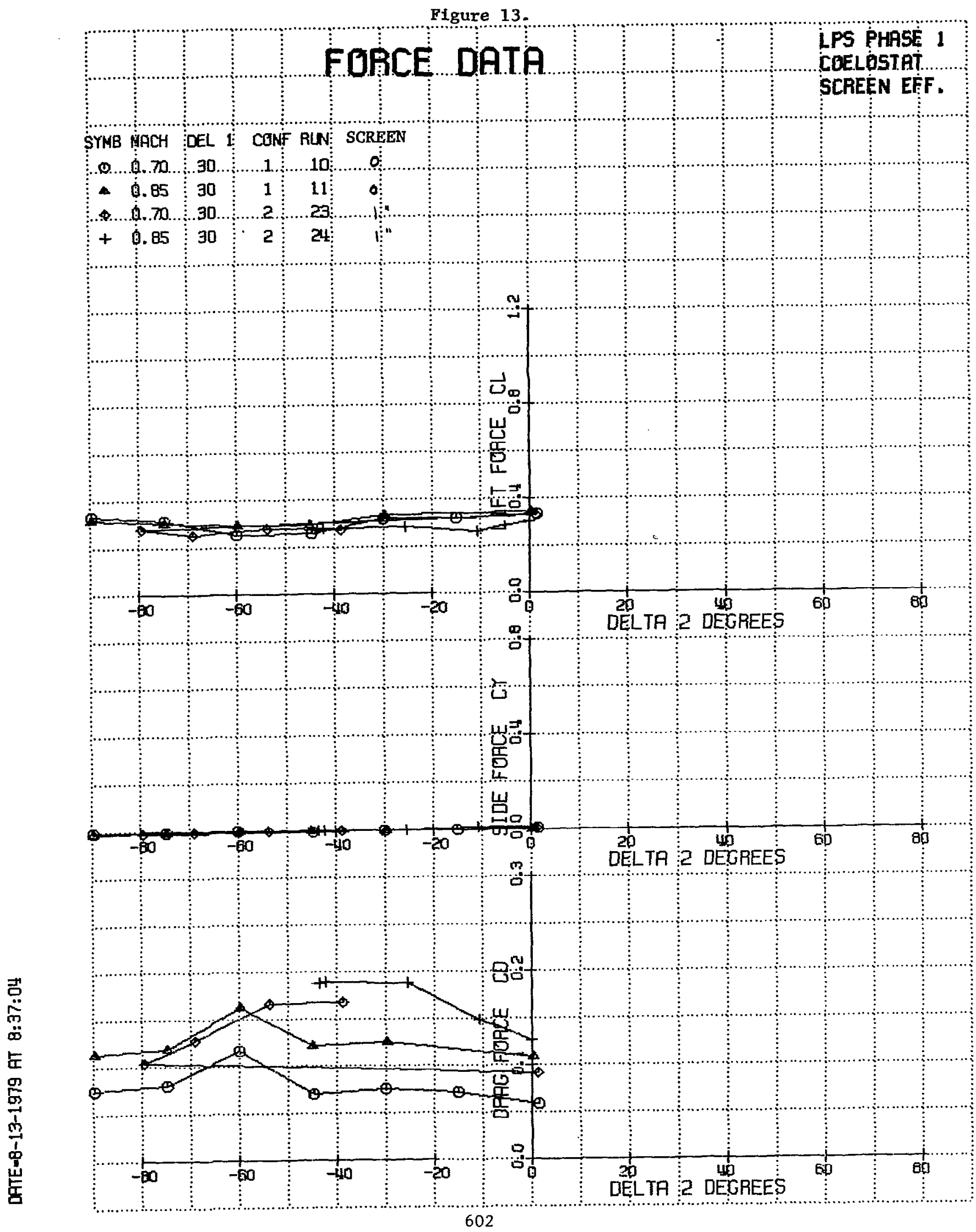




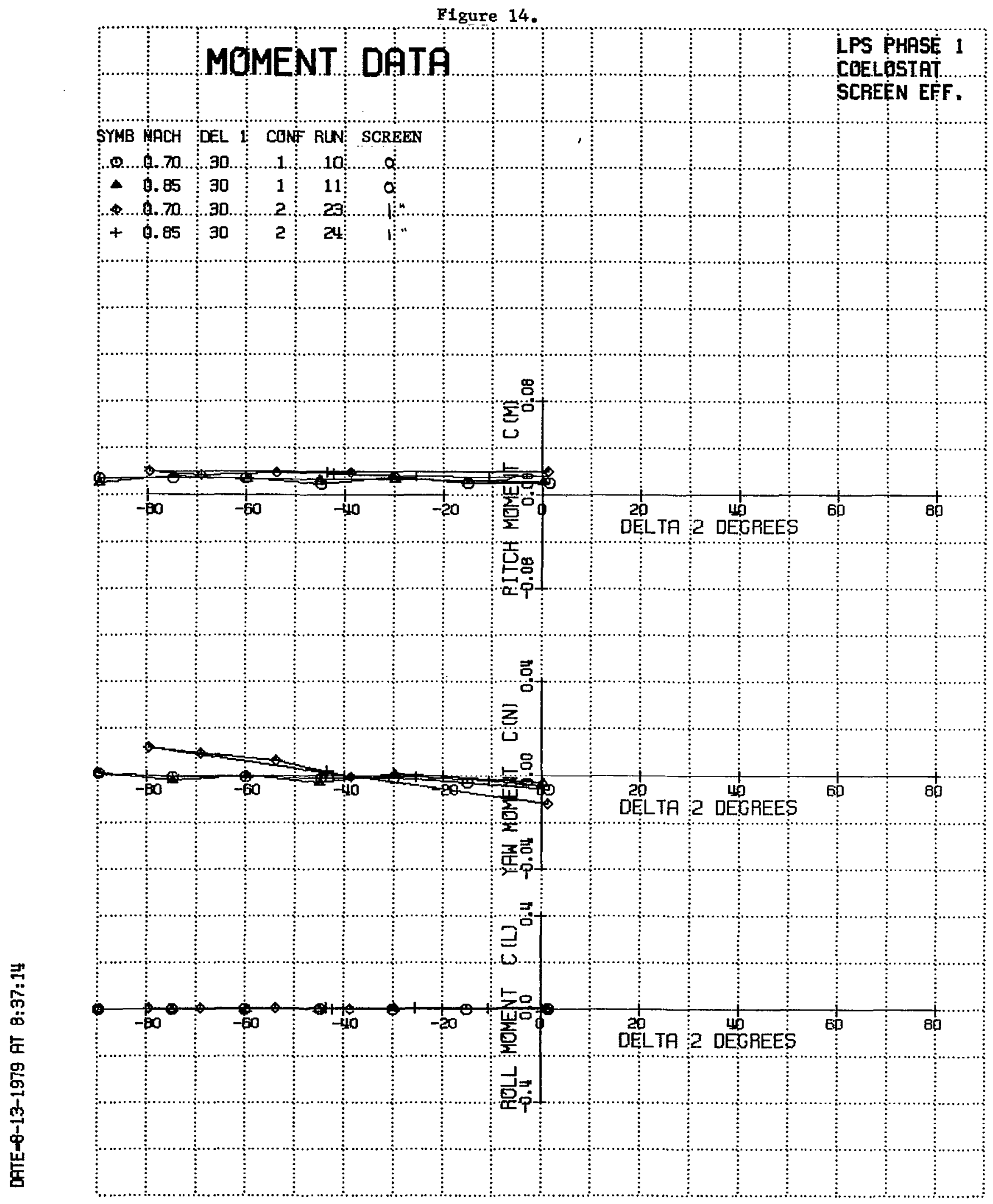




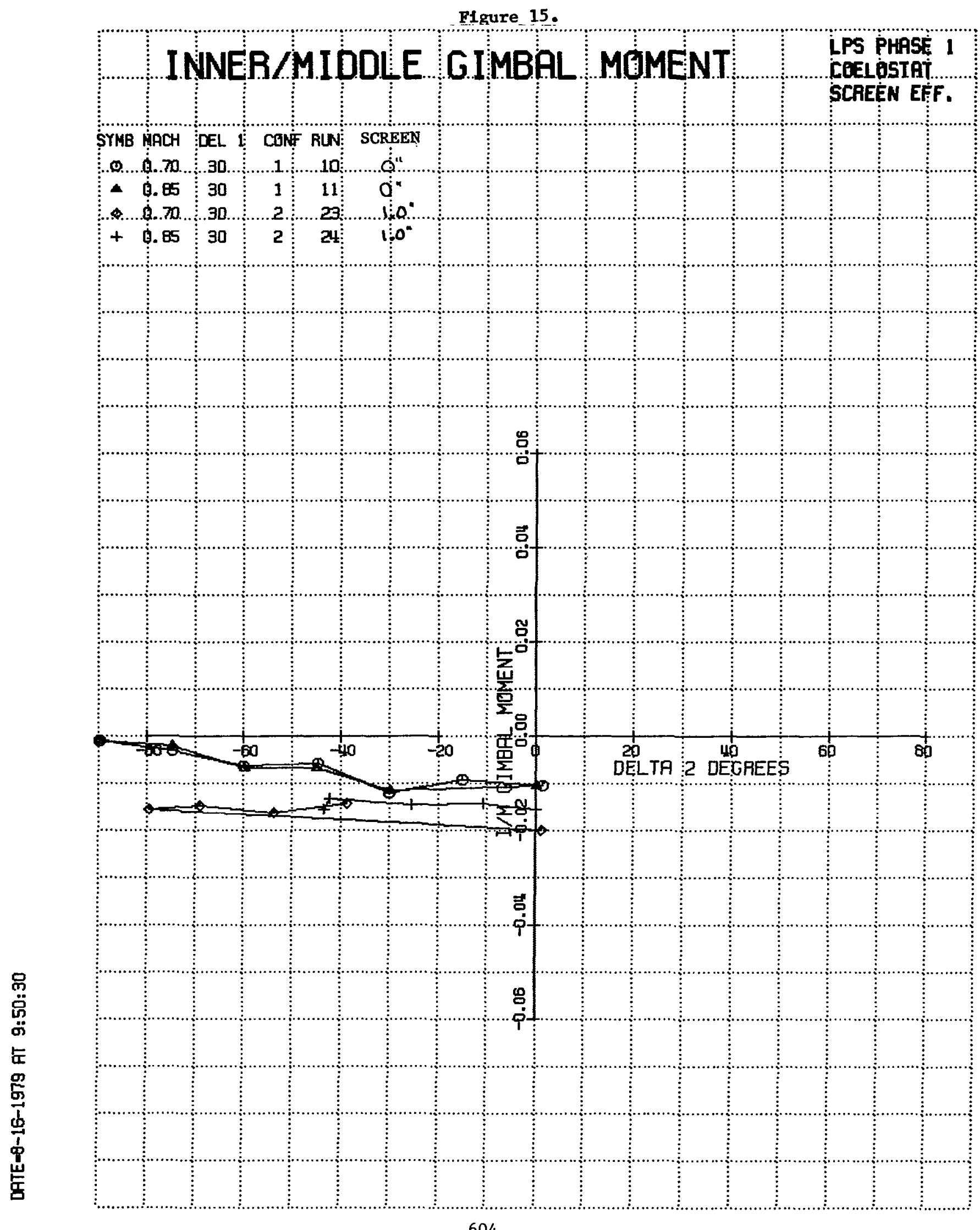


Figure 16.

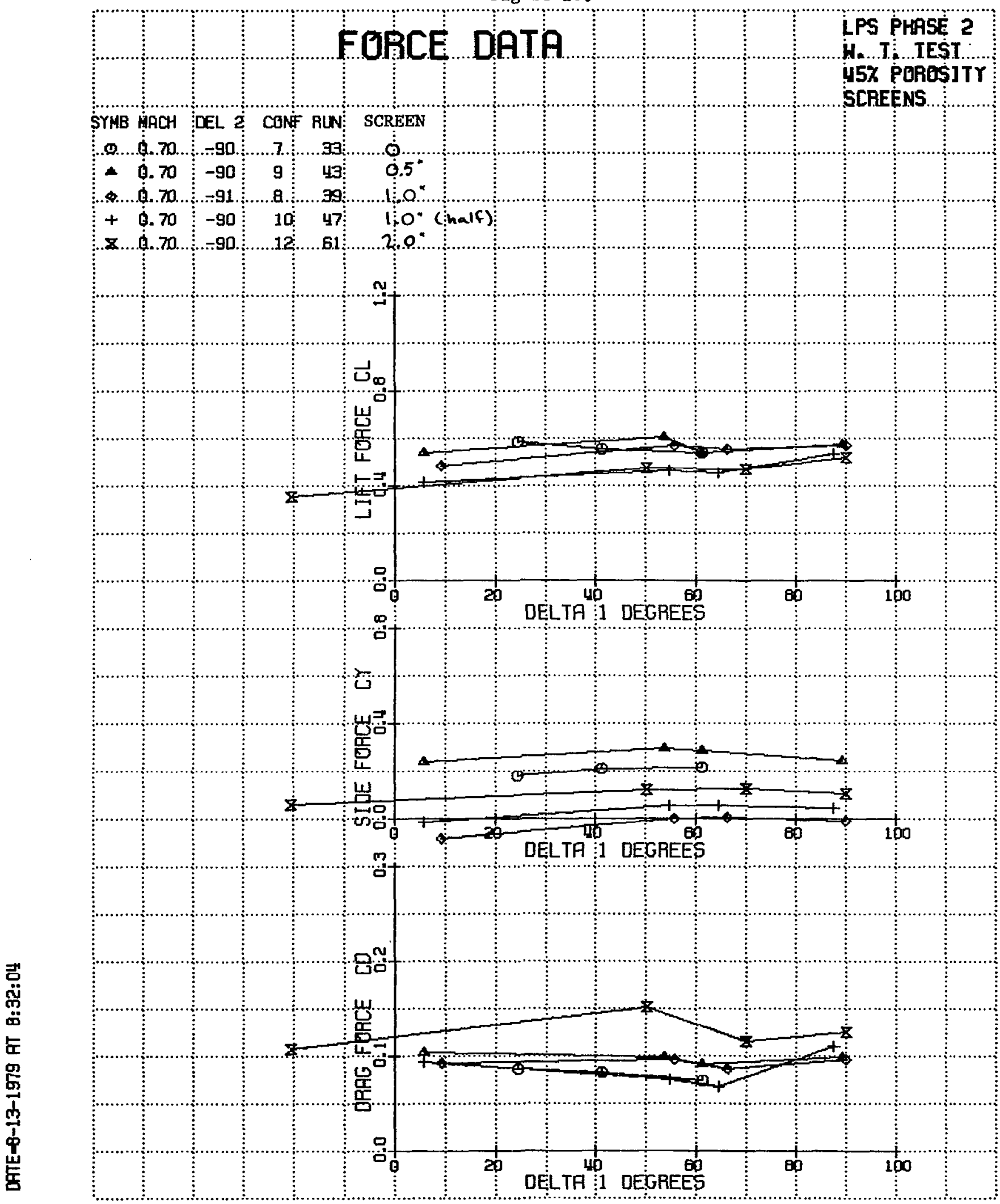


Figure 17.

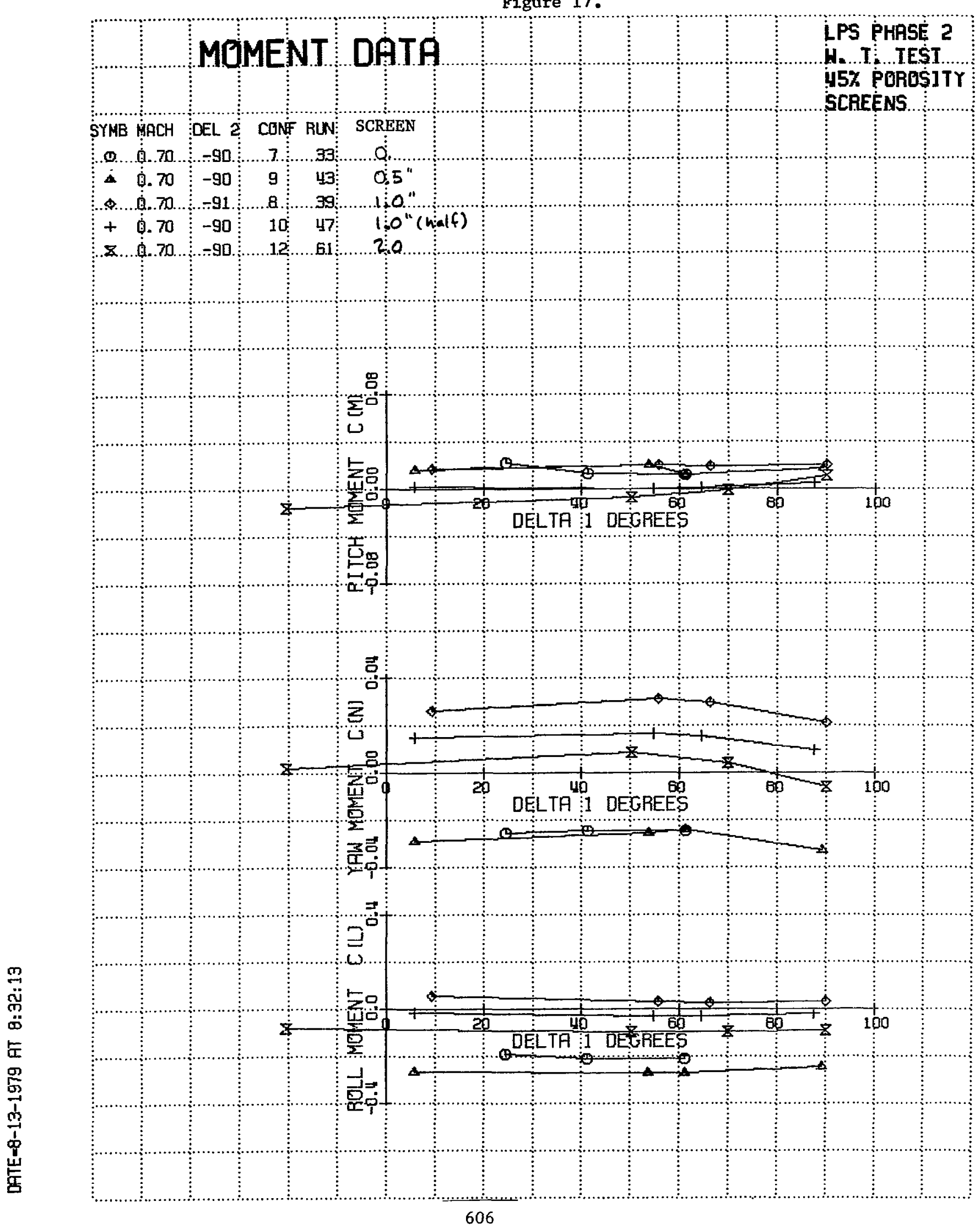




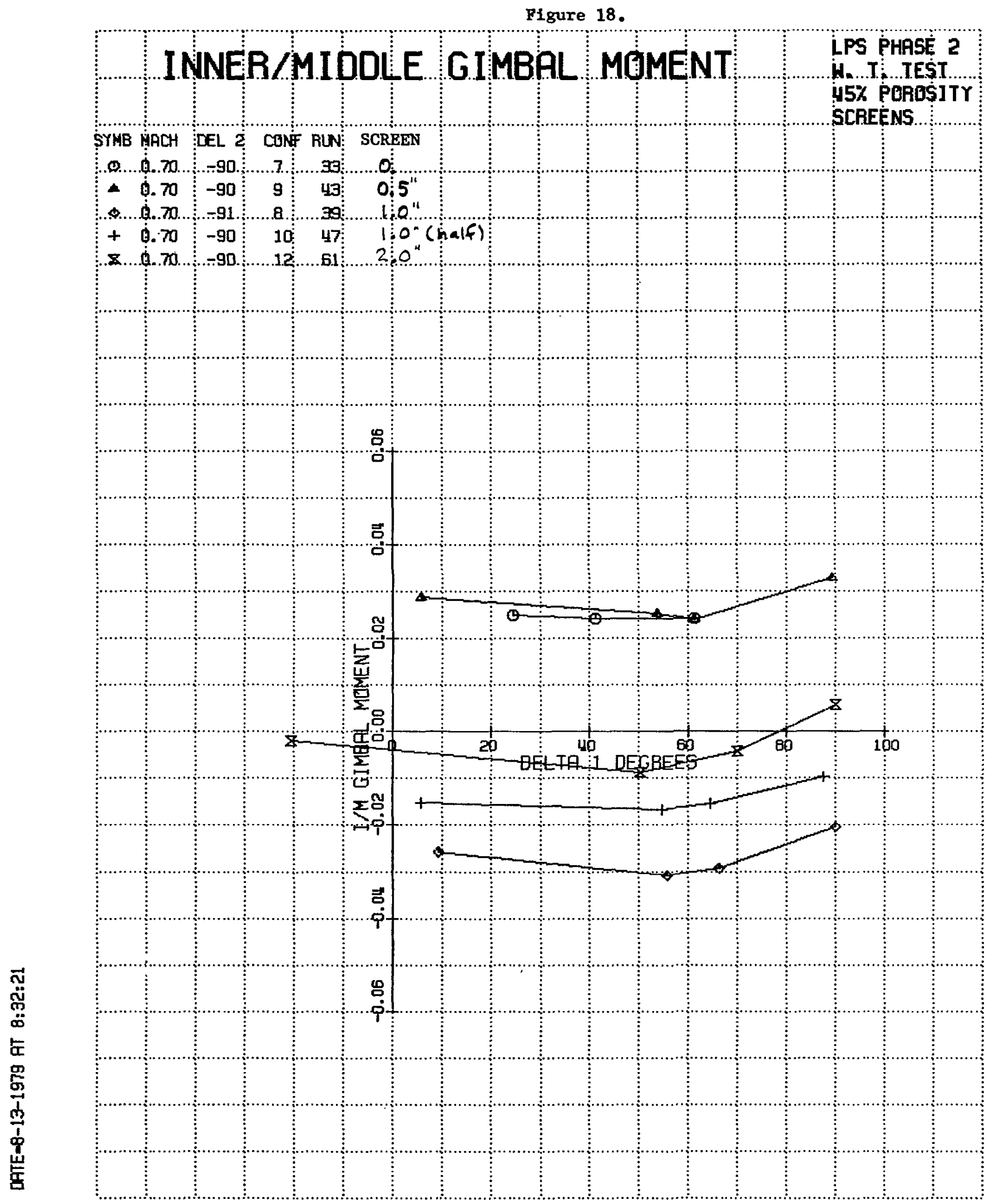




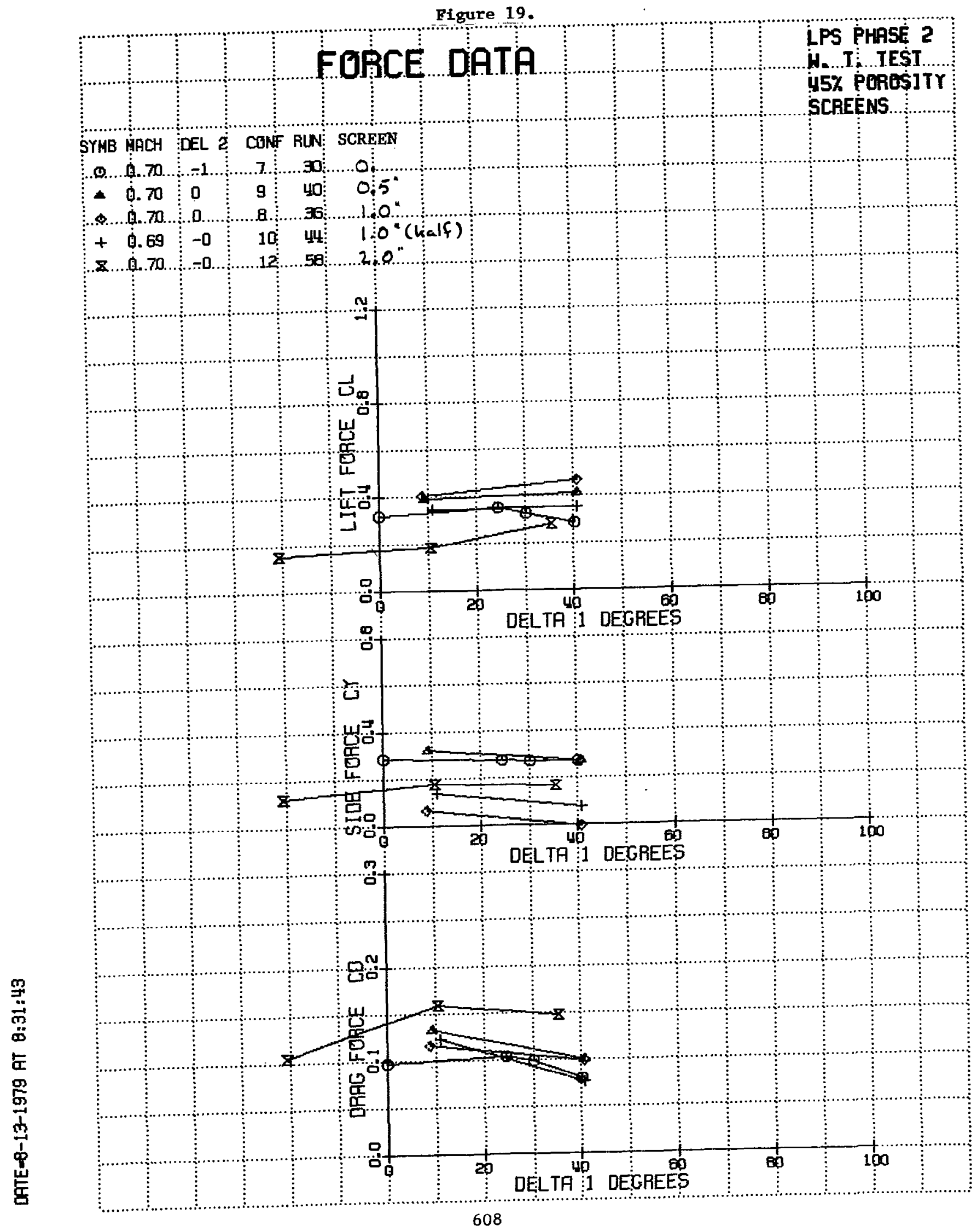




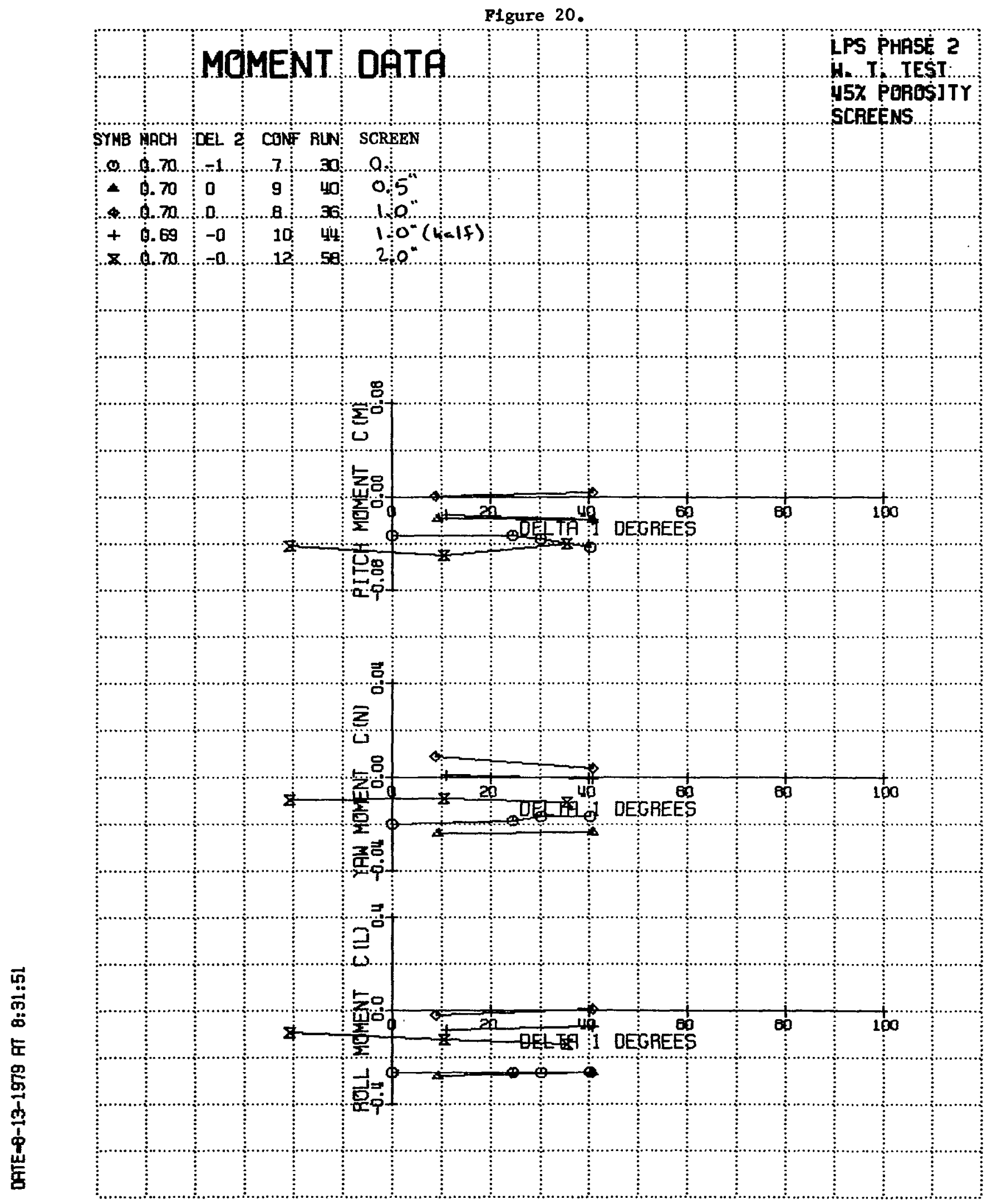


Figure 2I.

\section{INNER/MIDDLE GIMBAL MOMMENT \\ LPS PHASE 2 \\ H.... I...TEST \\ i5\% POROṠ]TY \\ SCREENS}

SYMB MACH DEL 2 CONF RLN SCREEN

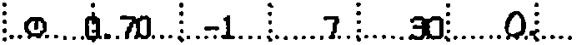

-

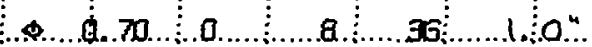

$+6.69-0 \quad 10^{\circ} 44 \quad 1.0^{\circ}$ (hialf)

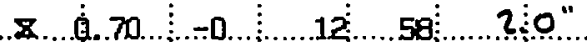




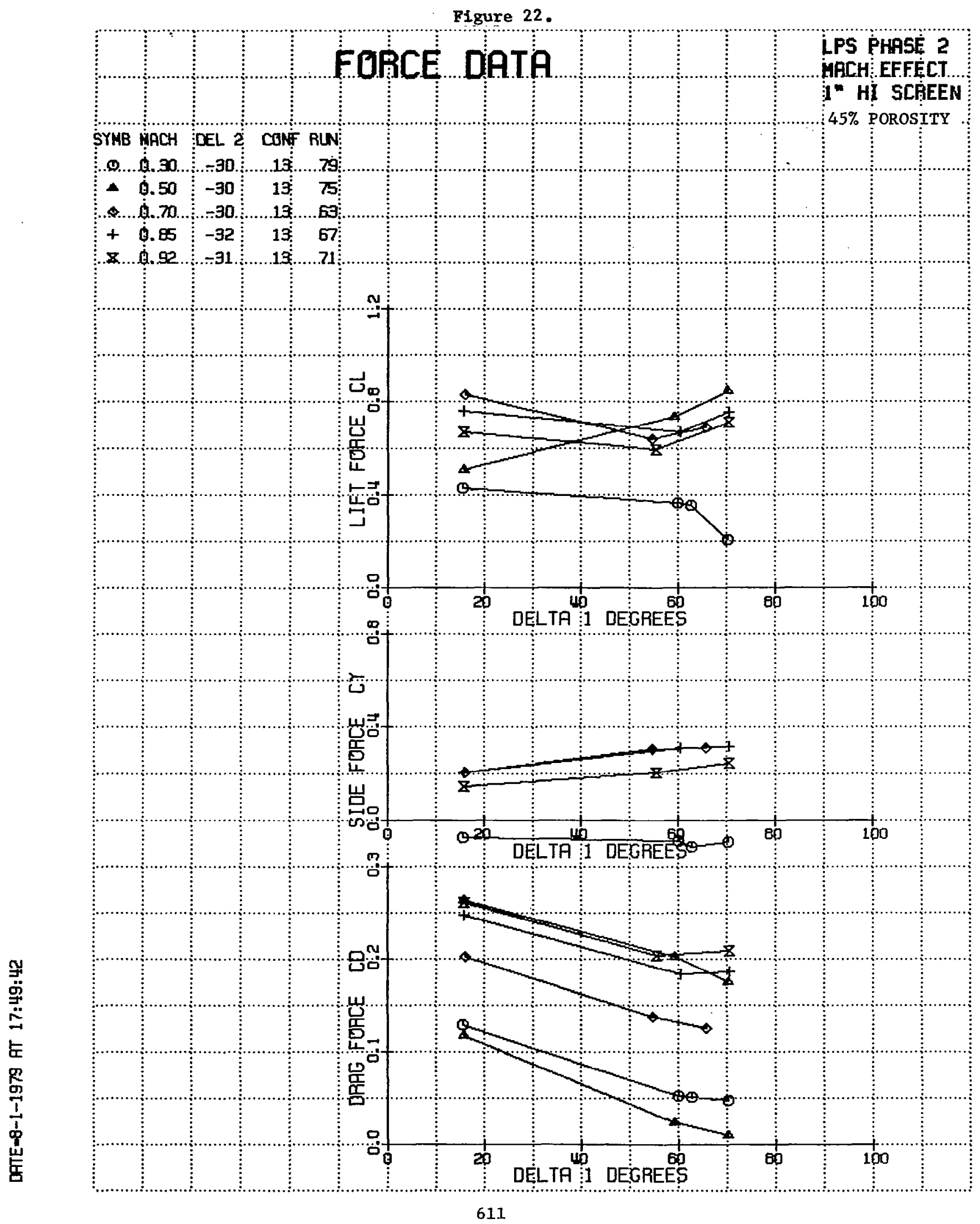




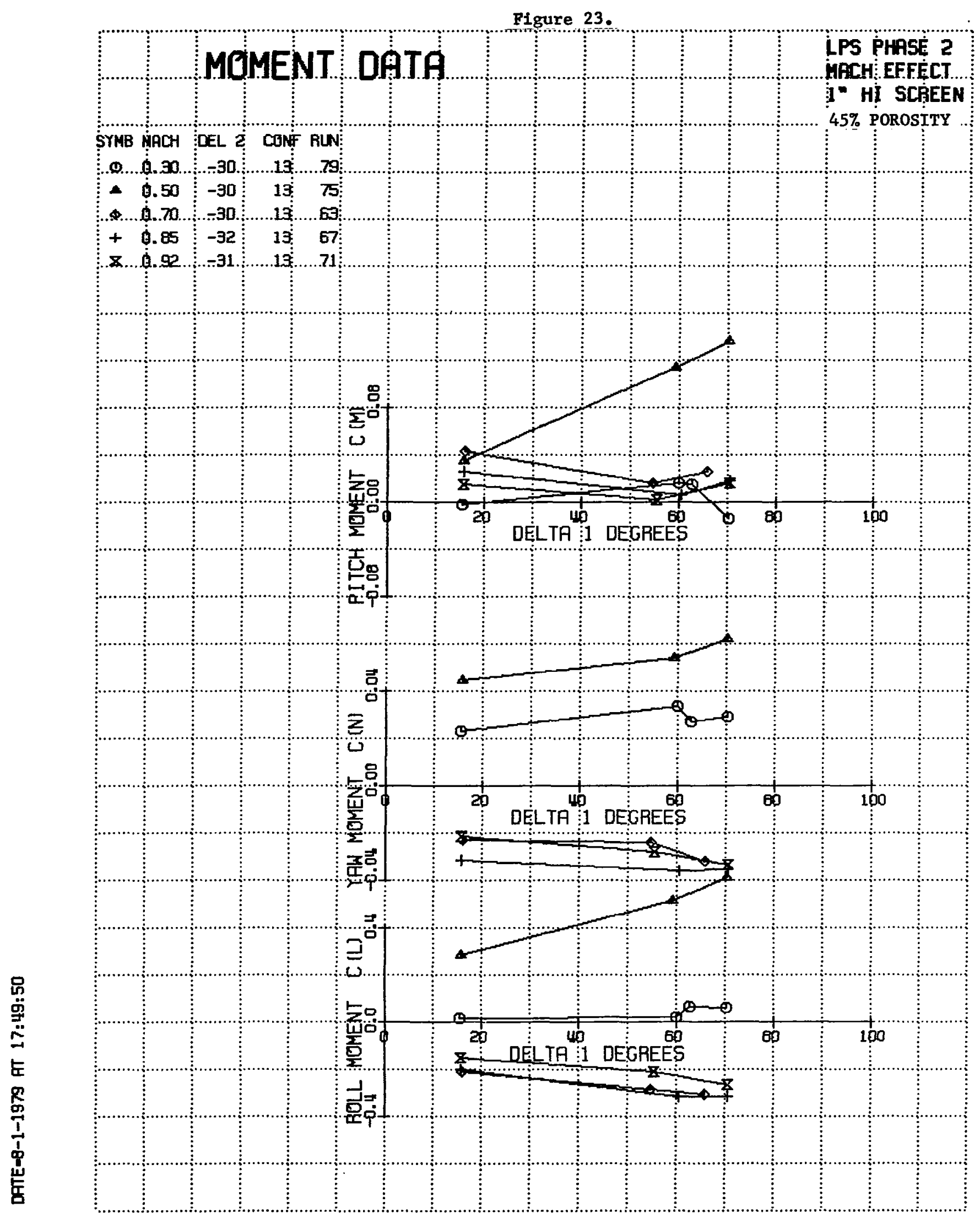




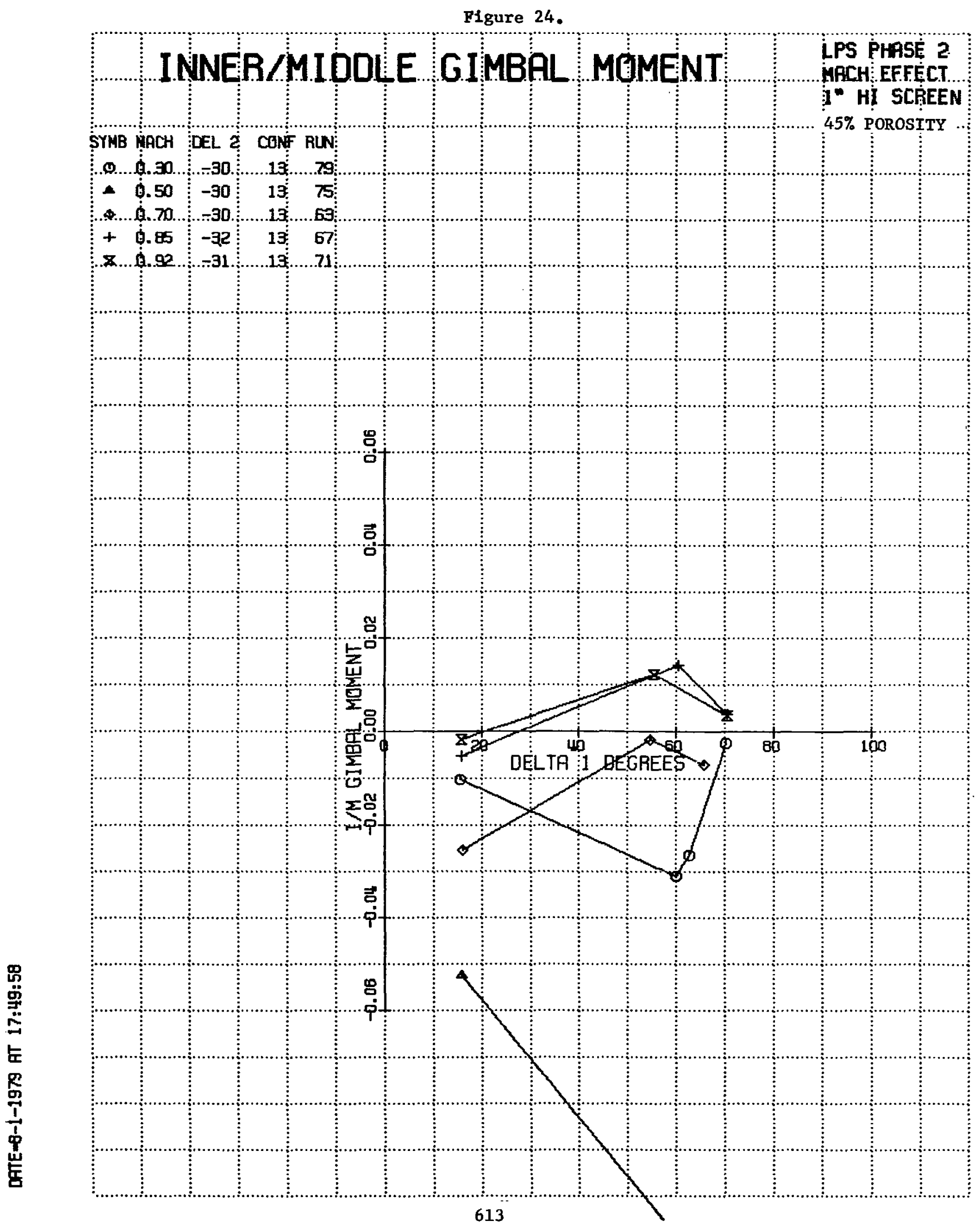

